\title{
Los profesionales de la salud y las consecuencias de una posible guerra en Irak: carta abierta al presidente del gobierno español
}

(Open letter to the Spanish government on Health professionals and the consequences of a possible war in Iraq)

\section{Sr. Director:}

En 1985 el presidente de la Asociación Internacional de Médicos para la Prevención de la Guerra Nuclear (IPPNW, o International Physicians for the Prevention of Nuclear War), el prestigioso cardiólogo Dr. Bernard Lown (copresidente de la organización junto con el Dr. Chazov) recibió en nombre de los miembros de esta organización el Premio Nobel de la Paz. En su discurso de aceptación del galardón, el Dr. Lown hizo la siguiente afirmación: «Nosotros, los médicos, nos manifestamos en contra del ultraje que representa mantener como rehén al mundo entero. Nos manifestamos en contra de la obscenidad moral de que cada uno de nosotros seamos continuamente candidatos a la extinción. Nos manifestamos en contra del número creciente de matanzas en el mundo. Nos manifestamos en contra de la expansión de la carrera armamentística en el espacio. Nos manifestamos en contra de desviar los escasos recursos existente de las dolorosas necesidades humanas. El diálogo sin hechos trae la calamidad más cerca que nunca, ya que la lentísima acción de la diplomacia se ve desbordada por la tecnología de los misiles. Nosotros, los médicos, demandamos actos que conduzcan a la abolición de las armas nucleares ${ }^{1}$.

Los acontecimientos mundiales sugieren que es necesario que los médicos y los profesionales de la sanidad usemos nuestra voz autorizada, ya que se nos asigna la responsabilidad de cuidar de nuestros conciudadanos desde el nacimiento hasta la muerte, para advertir a la población y a nuestros gobernantes de los peligros gravísimos de la guerra a gran escala, incluya o no armas nucleares.

Nuestros colegas británicos ya han advertido a su presidente de las consecuencias de una guerra en Irak²: más de 260.000 personas pueden morir en el conflicto. Si se produce una guerra civil en Irak, habría que añadir otras 20.000 muertes. Las relacionadas con la posguerra podrían sumar 200.000. En todos los escenarios posibles la mayoría de las víctimas serán civiles, a causa del hambre, las epidemias, los efectos directos de la guerra y los desplazamientos de refugiados que se estiman en casi un millón de personas. Todo lo cual propiciará, además, efectos catastróficos sobre la salud infantil, el medio ambiente y sobre el desarrollo de las zonas implicadas a largo plazo. Además, hay que añadir a esta lista el efecto impredecible que puede tener esta acción de guerra en la escalada de violencia que vive el mundo ${ }^{3}$.

En el siglo pasado murieron más de 120 millones de personas víctimas de las guerras y de los genocidios. Nos preguntamos si nuestra generación volverá a dejar a la siguiente la histórica vergüenza de no haber sabido convencer en lugar de vencer, y de socorrer en lugar de aniquilar por acción o por omisión. La violencia es el recurso del incompetente: no podemos creer que quienes nos gobiernan no sepan usar su inteligencia y convocar la de sus ciudadanos más destacados para imaginar soluciones mejores que la guerra para las amenazas del terrorismo. Los recursos de marketing, los eufemismos o simplemente la demagogia no pueden sustituir la fuerza de la verdad y la fundamentación de las acciones de los gobiernos en principios éticos, democráticos y humanitarios.

La Corte Penal Internacional, cuyo estatuto se firmó en Roma el 17 de julio de 1998, entró en vigor en julio de 2002 con la ratificación de España, el Reino Unido y otros 137 estados. En este tribunal internacional quedan establecidas las bases de un tribunal supranacional encargado de llevar ante la ley varios tipos de crímenes: los de lesa humanidad, los de genocidio, los de guerra, los crímenes de carácter sexual, la esclavitud, el apartheid y el uso de niños menores de 15 años en conflictos armados ${ }^{4}$. Este tribunal debería ser el encargado de juzgar a los gobernantes que no sigan los principios descritos en el párrafo anterior, y los que se han adherido a él deberían cooperar en que todos los encausados por el tribunal sean juzgados. Es descorazonador que entre los diversos países que se niegan a ratificarlo se encuentren los Estados Unidos de Norteamérica e Irak, pero aún es más desalentador que países que sí lo han hecho, como España y el Reino Unido, justifiquen, apoyen y faciliten acciones de Estados Unidos contra Irak.

Como consecuencia de lo expuesto, como profesionales responsables de la salud de los ciudadanos, y alejados de cualquier convicción religiosa o política, pedimos al gobierno español y a los de las comunidades autónomas que no apoyen una guerra en Irak ni en ningún otro país, y que utilicen los recursos legales y diplomáticos bilaterales e internacionales con toda la intensidad que les permite la legitimidad de haber sido votados por ciudadanos que confían en que ejercerán sus funciones desde la ética, la solidaridad y el humanitarismo. 
Jaume Marrugat, Núria Solanes, Miquel Porta, Esteve Fernández, Gloria Pérez, Roberto Elosua, Antonio Plasencia, Marina Pollán, Josep Alfons Espinás, Carlos Alberto González, Núria Ribas, Sandra Pérez, Jan Paul Zock, Esther Callizo, Gemma Castaño, Antonia Domingo, Judith García, Rosalía Santed, Ferran Ballester, Elisabet Puidollers, Salvador Peiró, Angels Pont, Carlos Alvarez-Dardet, Elisabet Luquin, María José Tormo, Oriol Vall, Xurxo Hervada, Teresa Brugal, Rafael Manzanera, Josep Roca, Luís Carlos González, Jesús Vioque, Santiago Pérez, Xavier Castellsagué, Anna Schiaffino, Enric Durán, Silvina Berra, Francesc Macià, Marisa Rebagliato, Luís Rajmil, Mercè Peris, Montserrat Vergara, Maria Sala, Alba Ribalta, Joaquim Gea, Andreu Segura, Mercè Medina, Josep Maria Jansà, Ildefonso Hernández, María Isabel Covas, Josep Fusté, Joan Benach, Constança Albertí, Fèlix Bosch, Dolors Marín, Gemma Cucó, Izabella Rohlfs, Pere Godoy, Carmen Cabezas, Catherine Pérez, Lluís Serra, Celsa López, Carlos Ariza, Beatriz Pérez, Oscar Zurriaga, Julia del Amo, Esther Llop, Anna Rodés, Jordi Ortuño, Agustín Montes, Carlos Artundo, María Isabel Pasarín, Rosa Cano, Juan Bellido, Víctor
Abraira, Gonzalo López-Abente, Agustín Gómez de la Cámara, Esther Menoyo, Antonia Galmés, Gregorio Barrio, Montserrat Ferrer, Carmen García, Gonzalo Gutierrez, Ana Álvarez, Karoline Fernández, Juan José Criado, María José Rabanaque, Pablo Martínez, Rodolfo Saracci, Josep Maria Manresa, Ignacio Rosell, Carlos Aibar, Juan Martínez, Carmen Navarro, Rocío García, José Luís Arocha, Teresa Vázquez, Joan Sala, Rafael Masiá, Mariano Sentí, Montserrat Fitó, Yolanda Ferrer, Bernard Lown.

Puede adherirse al contenido de esta carta y ver la lista completa de firmantes en: www.regicor.org/carta.htm

Correspondencia: Dr. Jaume Marrugat

Unitat de Lipids i Epidemiologia Cardiovascular.

Institut Municipal d'Investigació Mèdica.

C/ Dr. Aiguader, 80. 08003 Barcelona

Correo electrónico: jmarrugat@imim.es

\section{Bibliografía}

1. 1985 Nobel Peace Prize Acceptance Speech. Disponible en: http://www.ippnw.org/Lown.html (Accessed 31 Jan 2003).

2. Carolyn $S$ y 500 firmantes más. Open letter to Tony Blair: call to prevent escalating violence. BMJ 2003;326:220.

3. Medact. Collateral damage: the health and environmental costs of war on Iraq. Disponible en: www.medact.org/tbx/pages/ sub.cfm?id=556 (accessed 31 Jan 2003).

4. 1 de julio de 2002. Entrada en vigor del Estatuto de Roma Corte Penal Internacional. Disponible en: http://www.derechos.org/nizkor/impu/tpi/ (accessed 31 Jan 2003). 